\title{
Extracorporeal Circulation in Cardiac Surgery Inflammatory response, controversies and Future Directions
}

\section{Abstract}

One of the milestones in the history of the cardiac surgery is the development of extracorporeal circulation, which allowed hundreds of thousands of patients under successful open cardiac surgery. It's objective is to maintain the vital organ's perfusion, provide a bloodless field for surgery, and at the same time, give protection to the heart and lungs. Its principle is to bring most or all of the patient's systemic blood, which normally returns to the right atrium, into an oxygenator in which oxygen is supplied to the blood and carbon dioxide is removed. The arterialized blood is filtered, heated and, pumped into the aorta and the systemic arterial system. But this continuous blood recirculation through nonendothelial surfaces of the perfusion system produces an inflammatory response. Despite all the advantages and strategies developed to try to make the most physiological condition during the extracorporeal circulation, there are still persistent controversies, which we are going to review, as well as the inflammatory response produced by the perfusion system, and it's future directions.

\section{Keywords}

Extracorporeal circulation, cardiopulmonary bypass, inflammatory response, ECMO, Mini-cardiopulmonary bypass
Christian Ortega Loubon, Yolanda Carrascal Hinojal, Enrique Fulquet Carreras, Gregorio Laguna Nuñez, Pilar Pareja Peláez, Miriam Blanco Sáez, Manuel Fernández Molina

1 Department of Cardiac Surgery. University Clinic Hospital of Valladolid, Spain. Ramon y Cajal, Ave 3. 47005.

Contact information:

Christian Ortega-Loubon, Department of Cardiac Surgery. University Clinic Hospital of Valladolid, Spain.

Tel: (34) 983420000

Fax: (34) 983257511

Address: Ramón y Cajal Avenue, 3. 47005 Valladolid, Spain.

”christlord26@gmail.com

\section{Introduction}

The application of physiologic investigations has lead to such dramatic advances in open cardiac surgery that unexpected observations and new facts have come from operating rooms and not from experimental laboratories. [1]

The urgent need for surgical repair in congenital and acquired heart disease provided the vigorous and impetus needed to become the 
artificial heart and lungs machine a reality. This opened a vast and almost unexplored field for cardiac surgeons. [2]

\section{History}

Certainly, one of the milestones in the history of the cardiac surgery is the cardiopulmonary bypass (CPB). This allowed unimaginable accomplishment, previously thought impossible, such as performing an open cardiac surgery. A few years later, many patients a year undergo successful cardiac surgery with excellent clinical outcomes. It is hard to single out one investigator or one discovery which has made this brave, new world of cardiac surgery possible because it is the result of a century long brilliant intellectual curiosity. Lasting credit goes to the vision and perseverance of Gibbon who developed the principle of blood filming and reported the maintenance of life during clamping of the pulmonary artery in 1937, the first series of consecutively surviving dogs after total CPB in 1952 and the first successful human application on May 18, 1953, when he repaired an atrial septal defect in a young woman totally supported using a pump oxygenator. [3, 4]

C. Walton Lillehei and colleagues, who used a method of cross circulation, convincingly demonstrated that life could be supported by artificial means while the heart and lungs were temporarily excluded from the circulation. They brought into being the modern era of open cardiac surgery. 2 John Kirklin first used a CPB with a pump oxygenator at the Mayo Clinic on March 22, 1955.5

Pump oxygenator for cardiac surgery had to await development of modern anesthesia, modern surgical methods, and scientific developments such as discovery and use of heparin and manufacture of biocompatible plastic materials. [6]

The principle of CPB is that most or all of the patient's systemic blood, which normally returns to the right atrium, is derived into a device in which oxygen is supplied to the blood and carbon dioxide is removed. This arterialized blood is pumped from the device into the aorta. Complexities of CPB include that blood does not naturally circulate through nonendothelially-lined channels, contain gaseous and particulate emboli, experience nonphysiologic shear stresses, absence of any appreciable pulmonary blood flow and minimal pulsatile aortic pressure. [6]

It can be adapted to provide partial or total circulatory and respiratory support. Total CPB is when all the venous blood returns to the pump oxygenator instead of the heart. Partial CPB is when some systemic venous blood returns to the right atrium and ventricle, and is pumped into the lungs, then passes back into the left heart and pumped into the aorta.

\section{Components}

The components include: venous cannula, reservoir, pump, membrane/oxygenator/heat exchanger, microfilter-bubble trap, arterial cannula, and the patient is positioned in between. All the tubing and connections must allow the blood flow path smooth and uniform, without areas of stenosis, kinking or expansion. [7]

Depending on the operation, various suction systems are used to return blood from the surgical field. Aspirated blood passes through a cardiotomy reservoir and microfilter before returning to the venous reservoir. It is recommended, field blood be washed in a cell saver system and returned to the perfusate as packed red cells. Sites for obtaining blood samples and sensors for monitoring pressures, temperatures, oxygen saturation, blood gases, and $\mathrm{pH}$ are included, as are various safety devices. [8]

A separate circuit for administering cardioplegic solutions at controlled composition, rate, and temperature is usually included in the system.

\section{Venous Input}

Venous blood usually enters the circuit by gravity or siphonage into a venous reservoir placed 40 to 
$70 \mathrm{~cm}$ below the level of the heart. The amount of drainage is determined by central venous pressure; the height differential; resistance in cannulas, tubing, and connectors; and absence of air within the system. [8]

\section{Venous Reservoir}

Serves as a receiving chamber for venous return, facilitates gravity drainage, is a venous bubble trap; provides a convenient place to add drugs, fluids, or blood; and adds storage capacity for the perfusion system, that if the venous return is suddenly stopped, the reservoir can provide a continuous perfusion during several seconds. [7]

\section{Oxygenator}

Not only regulates the gases tension in the arterial blood, but also, is the largest area of foreign surface blood comes into contact with, and therefore where the most blood damage occurs. There are two types: membrane and bubble oxygenators. Membrane oxygenators imitate the natural lung by interspersing a thin membrane of either microporous $(0.3$ - to $0.8-\mu \mathrm{m}$ pores) between the gas and blood phases. Compared to bubble oxygenators, membrane oxygenators are safer, produce less particulate and gaseous microemboli, are less reactive to blood elements, and allow superior control of blood gases. [9-11]

Arterial partial carbon dioxide pressure $\left(\mathrm{PaCO}_{2}\right)$ is controlled by gas flow, and arterial partial oxygen pressure $(\mathrm{PaO} 2)$ is controlled by the fraction of inspired oxygen (FIO2) produced by an air-oxygen blender. $\mathrm{PaO} 2$ is related to temperature of the patient, which is related to oxygen consumption (VO2).

Some clinical perfusions for cardiac surgery are performed at normothermia $\left(\approx 37^{\circ} \mathrm{C}\right)$ and others at various levels of hypothermia: mild $\left(30^{\circ} \mathrm{C}-35^{\circ} \mathrm{C}\right)$, moderate $\left(25^{\circ} \mathrm{C}-30^{\circ} \mathrm{C}\right)$, or deep $\left(<25^{\circ} \mathrm{C}\right)$. Therefore, it is necessary to consider the strategy for controlling $\mathrm{PaCO}_{2}$ and, indirectly, pH.5
Hypothermia is used in some cases, for example, when a complete circulatory arrest is needed, because it reduces metabolic activity to the extent that available energy stores in the various organs maintain cell viability throughout the ischemic period of circulatory arrest and thus allow normal structure and function to return after reperfusion. The patient's body temperature is the most important determinant of the length of safe circulatory arrest time.

\section{Heat exchanger}

Control the body temperature by heating or cooling blood passing through the perfusion circuit. Hypothermia is frequently used during cardiac surgery to reduce oxygen demand or to facilitate operative exposure by temporary circulatory arrest. Gases are more soluble in cold than in warm blood; therefore, rapid rewarming of cold blood in the circuit or body may cause formation of bubble emboli.12 Blood is not heated above $40^{\circ} \mathrm{C}$ to prevent denaturation of plasma proteins, and temperature differences within the body and perfusion circuit are limited to 5 to $10^{\circ} \mathrm{C}$ to prevent bubble emboli. A separate heat exchanger is needed for cardioplegia.

\section{Pumps}

There are three types: roller, impeller, and centrifugal. Roller pumps have two rollers $180^{\circ}$ apart. Impeller uses vanes on a rotating shaft, and centrifugal pumps uses three concentric cones. [13]

Roller pump is nearly occlusive, afterload independent, Its advantages are: require low prime volume, low cost, no potential for backflow. Disvadntages are: produce excessive positive and negative pressure that can cause tubing rupture, potential for massive air embolism, necessary occlusion adjustments, requires close supervision. Roller pumps are used for sucker systems, and for delivering cardioplegia.

Centrifugal pump is nonocclussive, afterload sensitive. Advantages: safe positive and negative pres- 
sure, adapts to venous return, superior for right of left heart bypass, preferred for long-term bypass, and protects against air embolism. Disadvantages: higher cost, potential passive backward flow, and require larger priming volume.

\section{Arterial Output}

Arterial outflow to the patient is achieved by generating a large pressure gradient by the pump. The most commonly used type of arterial pump is the roller pump. It generates a relatively nonpulsatile flow and is simple, reliable, and relatively inexpensive. In clinical use, roller pumps are generally set to be nearly occlusive. When they are occlusive, trauma to the formed elements in blood is increased; when they are too nonocclusive, they are unable to maintain the same rate of flow against the wide range of resistances (pressure differentials of 30 $300 \mathrm{mmHg}$ ) offered by arterial cannula and the patient's systemic vascular resistance.

The arterial line pressure must be continuously monitored. When exceeds 250 to $300 \mathrm{mmHg}$, increases risk of disruption of the arterial line and of cavitation in the region of the arterial cannula.

\section{Perfusate solution}

Require 1.5-2 $\mathrm{L}$ depending upon the preoperative hematocrit value. It is a balanced electrolyte solution with a near normal $\mathrm{pH}$ and an ion content resembling that of the plasma. Before connection to the patient, the prime is recirculated to remove air, represents $30-35 \%$ of the patient's blood volume and reduces the hematocrit to $2 / 3$ of the preoperative value. The use of colloids in the priming solution is controversial. [14]

\section{Filter}

During CPB the wound and the perfusion circuit generate gaseous, biologic and nonbiologic microemboli particulates. Sources of gas entry include stopcocks, sampling and injection sites,15 priming solutions, priming procedures, intravenous fluids, vents, the cardiotomy reservoir, tears or breaks in the perfusion circuit, loose purse-string sutures (especially during augmented venous return),16 rapid warming of cold blood,12 cavitation, oxygenators, venous reservoirs with low perfusate levels. [17, 18]

There are many potential sources of microemboli. Blood produces emboli related to thrombus formation (clots), fibrin, platelet and platelet-leukocyte aggregation, hemolyzed red cells, cellular debris, and generation of chylomicrons, fat particles, and denatured proteins. [7]

To prevent microemboli formation: membrane oxygenator, centrifugal arterial pump, cardiotomy reservoir filter, arterial line filter, keep temperature differentials $<8-10^{\circ} \mathrm{C}$, primer with Carbon Dioxide flush, prevent air entry into the circuit (snug pursestring sutures, three way stopcocks on all sampling ports, avoid excessive suction on vents), wash blood aspirated from surgical field,19 prevent thrombus formation with adequate anticoagulation, assess inflow cannulation by epiaortic ultrasound imaging, consider use of special aortic cannulas with20-22 or without baffles or screens to reduce the number of atherosclerotic emboli. [23]

\section{Microfilters}

The brain receives $14 \%$ of the cardiac output and is the most sensitive organ for microembolic injury. Strategies to selectively reduce microembolism to the brain include reducing $\mathrm{PaCO}_{2}$ to cause cerebral vasoconstriction; hypothermia; placing aortic cannulas downstream to the cerebral vessels; and using special aortic cannulas with or without special baffles or screens designed to prevent cannulaproduced cerebral atherosclerotic emboli.

As compared to no filter, studies indicate that all commercial filters effectively remove gaseous and particulate emboli. Filters cause slight hemolysis and tend to trap some platelets; nylon filters may activate complement.

The need for microfilters in the cardiotomy suction reservoir is universally accepted, and most com- 
mercial units contain an integrated micropore filter. Moreover, as compared to perfusion microemboli, surgically induced emboli are more likely to cause postoperative neurologic deficits.

\section{Cardiotomy Reservoir}

Here is storage all the blood aspirated from the surgical field for defoaming, filtration before be added directly to the perfusate. Represent the major source of hemolysis, particulate and gaseous microemboli, fat globules, cellular aggregates, platelet injury and loss, thrombin generation, and fibrinolysis.24 This aspirated blood also goes to the venous reservoir.

\section{Venting}

During CPB, distension of either ventricular (major the left ventricle) is injurious when the heart is unable to contract, because increases the $\mathrm{O} 2$ demand, and therefore is detrimental to the subsequent contractility. 25 During CPB blood escaping atrial or venous cannulas, coronary sinus, thebesian veins may pass to the right ventricle to the pulmonary circulation. This blood plus blood from bronchial vessels, and from abnormal sources (foramen ovale or ductus) distend the left ventricle unless a vent catheter is used.

Locations used to vent: aortic root (which can also be used to administer cardioplegia after the ascending aorta is clamped), right superior pulmonary vein through the mitral valve into the left ventricle, direct venting of the left ventricle at the apex, and the main pulmonary artery, which decompresses the left atrium since pulmonary veins lack valves. $[26,27]$

\section{Cardioplegia}

A carrier that could be a crystalloid or preferable blood contain $\mathrm{K}+, \mathrm{Mg} 2+$, infused at temperatures around $4-37^{\circ} \mathrm{C}$, depending upon surgeon surgeon preference. Normothermic cardioplegia must be delivered almost continuously to keep the heart arrested; cold cardioplegia if infused intermittently from 15 to 20 minutes, into the aortic root proximal to the aortic clamped or retrograde into the coronary sinus in order to arrest the heart into diastole. Is delivered through a separate perfusion system that includes reservoir, heat exchanger, and a roller pump.

Antegrade cardioplegia is administered at 60-100 $\mathrm{mm} \mathrm{Hg}$, allow arrests within 30-60 seconds, delay indicates problems with the delivery or unrecognized aortic valve insufficiency. Retrograde cardioplegia delivered at $30-50 \mathrm{mmHg}$. Higher pressures may injure the coronary sinus. Its induction arrest is slower from 2-4 min, and may provide inadequate protection to the right ventricle. $[28,29]$

\section{Determinants of Safe Perfusion}

\section{Blood Flow Rate}

In normal conditions, cardiac output is determined by oxygen consumption, which is approximately 250 $\mathrm{mL} / \mathrm{min} .30$ The flow rate at $35-37^{\circ} \mathrm{C}$ and hematocrit of $25 \%$ is $2.4 \mathrm{~L} / \mathrm{min} / \mathrm{m} 2$. Hypothermia reduces oxygen consumption by a factor of 0.5 for every $10^{\circ} \mathrm{C}$ decrease in temperature.

There is no evidence from a benefit of pulsatile blood flow over nonpulsatile blood flow for short or long term CPB. [31]

Mixed venous oxygen saturation (SvO2) assesses the relationship between de $\mathrm{O} 2$ delivery and its consumption. Values below $60 \%$ indicate inadequate oxygen delivery and a whole body perfusion that is not meeting the patient's metabolic demands. [32]

\section{Arterial blood pressure}

Is determined by flow rate, blood viscosity (hematocrit), and systemic vascular resistance. It is not necessary to pharmacologically manipulate systemic vascular resistance during $C P B$, unless it is less than $40-50 \mathrm{mmHg}$, when the autoregulation of the brain is disrupted, and the cerebral blood flow may 
Vol. 8 No. 19 doi: $10.3823 / 1618$ decline appreciably, with a concomitant decrease in cerebral oxygen consumption. [33-35]

\section{Hematocrit}

When the hematocrit is abnormally high, oxygen content is high, but the increased viscosity tends to decrease microcirculatory blood flow. Hypothermia increases blood viscosity; therefore, at low temperatures, a lower hematocrit is more appropriate than at $37^{\circ} \mathrm{C}$. Hematocrit of about $20 \%$ to $25 \%$ may be optimal during moderately and deeply hypothermic CPB. During rewarming, a higher hematocrit may be desirable because of increased oxygen demands, and the higher apparent viscosity of a higher hematocrit is appropriate during normothermia. The ideal hematocrit remains controversial. In general, viscosity remains stable when percent hematocrit and blood temperature are equal (viscosity is constant at hematocrit 37\%, temperature $37^{\circ} \mathrm{C}$, or at hematocrit $20 \%$, temperature $\left.20^{\circ} \mathrm{C}\right)$. [36-38]

\section{Temperature}

Hypothermia allows use of lower pump flow rate with less hematocrit and blood trauma, protects the brain, achieves better myocardial protection and protection of other organs than normothermic CPB. Systemic hypothermia also provides a margin of safety for organ protection. The patient's body temperature is the most important determinant of the length of safe circulatory arrest time.

However, the ideal temperature for cardiac surgery is controversial.37 Hypothermia interferes with enzyme and organ function, aggravates bleeding, increases systemic vascular resistance, delays cardiac recovery, increases the risk of cerebral hypothermia. [39]

\section{pH Management}

Changes in temperature affect acid-base balance, which must be monitored and managed during deep hypothermia. Management of gas exchange during cooling is also controversial. There are two strategies, each have advantages and disadvantages.

The $\alpha$-stat strategy is based using the $\mathrm{pH}$ measured at $37^{\circ} \mathrm{C}$, non temperature-corrected, to maintain this ventilation level at any temperature. It allows the $\mathrm{pH}$ to increase during cooling. The $\alpha$-stat strategy results in optimal function of a number of important enzyme systems, including lactate dehydrogenase, phosphofructokinase, and $\mathrm{Na}+\mathrm{K}+\mathrm{ATPase}$. With this protocol, cerebral blood flow is lower, autoregulated and coupled to cerebral oxygen demand.

The $\mathrm{pH}$-stat strategy strives for the same values of $\mathrm{pH}$ and $\mathrm{PaCO}_{2}$, corrected to the temperature. This represents a state of respiratory acidosis and hypercarbia. This strategy increases the rate and uniformity of brain cooling. Cerebral blood flow increases, and pressure is passive and uncoupled from cerebral oxygen demand, but may expose the brain to a larger number of microemboli.

At a cellular enzyme level, the $\alpha$-stat strategy may be preferable, but which is preferable in clinical cardiac surgery in neonates, children, and adults is the subject of continued investigation and debate.40 The $\alpha$-stat strategy results in a lower $\mathrm{PaCO}_{2}$, which may adversely affect cerebral blood flow. This may be of particular importance for patients with cyanotic congenital heart disease for whom low $\mathrm{PaCO}_{2}$ may result in pulmonary vasodilatation in addition to cerebral vasoconstriction. Thus, there can be a steal of blood from the cerebral to the pulmonary vascular bed. pH-stat management results in superior neurologic outcome during deep hypothermic CPB and hypothermic circulatory arrest in pediatricians.41,42 The $\mathrm{pH}$-stat technique may depress cardiac function.

\section{Blood response. Coagulopathy.}

All biomaterial surfaces, including heparin-coated surfaces, are procoagulant; 43 A nonthromboge- 
nic synthetic surface remains undiscovered, and only the endothelial cell is truly nonthrombogenic. In normal state, the fluidity and integrity of the vascular system are established and maintained by equilibrium between procoagulants and anticoagulants factors. Endothelial cells anticoagulant activities include: production of t-PA, heparin sulfate, dermatan sulfate, protein $\mathrm{S}$, tissue factor inhibitor protein, thrombomodulin, prostacyclin, nitric oxide, and adenosine. When disrupted exhibit procoagulant activities: expression of tissue factor, production of collagen, elastin, laminin, fibronectin, thrombosopondin, von Willebrand factor, factor $\mathrm{V}$, platelet activating factor (PAF), factor IXa and factor $X$ a.

During CPB high concentration of heparin is needed to maintain the fluidity of blood: $3-4 \mathrm{mg} / \mathrm{kg}$ initial doses. Additional heparin is given as needed to achieve an ACT of greater than 400 seconds during normothermic $C P B$, and greater than hypothermic $\mathrm{CPB}\left(<30^{\circ} \mathrm{C}\right)$.

The continuous exposure of heparinized blood to the perfusion circuit and to the wound during clinical cardiac surgery produces an intense thrombotic stimulus that involves both the extrinsic coagulation pathway (tissue factor pathway) in the wound and the contact and intrinsic coagulation pathways in the perfusion circuit.

The extrinsic pathway is the major source of thrombin generation during CPB. This fact has encouraged strategies to reduce the amounts of circulating thrombin during clinical cardiac surgery by either discarding wound blood or by only salvaging red cells by centrifugation and washing in a cell saver. While there is no evidence that heparin-coated circuits reduce thrombin generation, there is strong evidence that discarding wound plasma or limiting exposure of circulating blood to the wound does reduce the circulating thrombin generation. [44]

Heparin does not directly inhibit coagulation, but is a cofactor of antithrombin. Antithrombin primary binds thrombin, its action on factor $\mathrm{Xa}$ and IXa is much slower. Heparin inhibits coagulation at the end of the cascade after almost all other coagulation factors have been activated. Thrombin is continuously generated and circulated despite massive doses of heparin in all applications of extracorporeal perfusion. [45]

This imperfect anticoagulant permits formation of microthrombi in the pump-oxygenator that can embolize to the patient. In rare cases, heparin can also produce adverse effect such as severe thrombocytopenia.

Thrombin has both procoagulant and anticoagulant properties.46 Apart from cleaving fibrinogen to fibrin, thrombin also stimulates endothelial cells to produce tissue plasminogen activator (t-PA), which is the major enzyme that cleaves plasminogen to plasmin; stimulates the production of nitric oxide and prostaglandin by endothelial cells. Thrombin in the presence of thrombomodulin activates protein $\mathrm{C}$, which in the presence of protein $\mathrm{S}$ destroys factor $\mathrm{Va}$ and VIIla.

Circulating thrombin is a powerful agonist and binds avidly to two specific thrombin receptors on platelets: Protease activated receptor (PAR-1) and glycoprotein Ib- $\alpha$ (GPIb- $\alpha$ ). As extracorporeal perfusion continues, C5a, C5b-9, hypothermia, platelet activating factor (PAF), interleukin-6, cathepsin $\mathrm{G}$, serotonin, epinephrine, eicosanoids, adenosine diphosphate (ADP) also activate platelets and contribute to their loss and dysfunction.

The initial platelet reaction to agonists is a shape changes from a discoid form to an extended pseudopods form, which expresses GPIb and GPIIb/IIla receptors. GPIIb/IIla receptors bind platelets to exposed binding sites on surface-adsorbed fibrinogen. This receptor also binds plasma fibrinogen molecules to form platelet aggregates. During ECP the circulating platelet load is reduced by dilution, adhesion, aggregation, destruction, and consumption. 


\section{Inflammatory Response}

Any surgery, like a trauma, represents an aggression and therefore triggers an acute inflammatory response. In cardiac surgery, the foreign surfaces is a fundamental inciting agent of damaging effects of $C P B$, leading by the oxygenator where is the surface of greatest direct contact with blood. It is next greater in the heat exchanger, next in filters, and least in tubing and reservoirs. [47]

Blood pumps, suction systems, abrupt blood acceleration and deceleration, and cavitation around the end of the arterial cannula generate shear stresses. Shear stresses damage erythrocytes, and leukocytes. Hemolysis and free hemoglobin increases proportionally to shear stresses. Negative pressure of sucker systems is more damaging to erythrocytes than positive ones.

For leukocytes, shear stresses not only increase leukocyte disruption but also increase degranulation and adherence and decrease aggregation, chemotactic migration, and phagocytosis in nondisrupted leukocytes.

In cardiac surgery, the continuous recirculating of the heparinized blood, the duration of the surgery, nonendothelial surfaces of the perfusion circuit, and the ischemic/reperfusion time, magnifies the inflammatory response.

The main blood elements involved in this acute defense reaction are contact and complement plasma protein systems, neutrophils, monocytes, endothelial cells, and platelets. These blood elements produce inflammatory and inhibitory cytokines, express cellular receptors that interact with specific cell signaling substances and other cells, and generate a host of vasoactive and cytotoxic substances. Normally these reactive blood elements mediate and regulate the inflammatory response,48 but during CPB this reaction is overwhelmed by the massive activation and recirculation of these reactive blood elements.

\section{Complement}

Three pathways activate this system of plasma proteins, but only the classical and alternative pathways are involved in CPB. The complement system is activated at three different times during CPB: during blood contact with nonendothelial cell surfaces and wound exudate containing tissue factor; after protamine administration at the end of CPB and formation of the protamine-heparin complex; and after reperfusion of the ischemic, arrested heart.

The heparin-protamine complex activates complement by the classical pathway. But, during CPB, the alternative pathway largely activates complement. The complement leads to the formation of the membrane attack complex C5b-9, the production of powerful anaphylatoxins ( $\mathrm{C} 3 \mathrm{a}, \mathrm{C} 4 \mathrm{a}$, and $\mathrm{C} 5 \mathrm{a}$ ) that increase vascular permeability, cause smooth muscle contraction, mediate leukocyte chemotaxis, facilitate neutrophil aggregation and enzyme release. C5b-9 may also activate platelets and promote platelet-monocyte aggregates.

C5a is the principal agonist for activating neutrophils and is a potent chemoattractant for neutrophils, monocytes, macrophages, eosinophils, basophils, and microglial cells. [49]

\section{Neutrophils}

Neutrophils are strongly activated during CPB. C5a is a potent chemotactic protein that induces neutrophil chemotaxis, degranulation, and superoxide generation. [50]

They migrate directionally toward areas of higher complement concentration, change their shape, and become more adhesive. Arrive at the scene of inflammation to begin the process of phagocytosis and release of cytotoxins from azurophilic granules: lysozyme, myeloperoxidase, cationic proteins, elastase, collagenases, proteinase 3, acid hydrolases, defensins, and phospholipase. Specific granules contain $\beta-2$ integrins, lactoferrin, lysozyme, type IV collage- 
nase, histaminase, heparanase, complement activator, alkaline phosphatase, and membrane- associated nicotinamide adenine dinucleotide phosphate (NADPH) oxidase.50 Circulation of these cytokines mediates many of the manifestations of the initially called "whole body inflammatory response", now "systemic inflammatory response syndrome."

\section{Monocytes}

Are activated during CPB and have a major role in thrombin formation as associate with plasma tissue factor to rapidly accelerate the conversion of factor VII to factor VIla. Are the major source of the early response cytokines IL-1-beta and TNF- $\alpha$, IL-8, which induces neutrophil chemotaxis. [48]

\section{Endothelial cells}

The principal agonists for endothelial cell activation during $\mathrm{CPB}$ are thrombin, $\mathrm{C} 5 \mathrm{a}$, and the cytokines IL$1-\beta$ and TNF- $\alpha .51 \mathrm{IL}-1-\beta$ and TNF- $\alpha$ induce endothelial cell production of the chemotactic proteins IL-8 and MCP-1, and induce production of prostaglandin 12 and nitric oxide. [52]

\section{Platelets}

Contribute to the inflammatory by synthesis and release of eicosanoids, 53 serotonin from dense granules; IL-1- $\beta$; Platelet factor 4 (PF4), neutrophil-activating protein-2, IL-8, and endothelial cell neutrophil attractant-78; and macrophage inflammatory protein-1a, Monocyte chemoattractant protein 3 (MCP3), and RANTES from a granules. [54]

\section{Cytokines}

IL-1 $\beta$, TNF- $\alpha, I L-8$, MCP-1, IL-6 are the major proinflamatory cytokines involved in the inflammatory response. IL-10 is the major anti-inflammatory cytokine during $\mathrm{CPB}$. Proinflammatory cytokines increase during $C P B$, but peak concentrations occur 12 to 24 hours after CPB ends. APOE4 allele, one of the gene encoding apolipoprotein $E$, is associated with increased TNF- $\alpha$ and IL-8
The magnitude of this defense reaction during and after CPB is influenced by many exogenous factors that include the surface area of the perfusion circuit, the duration of blood contact with extravascular surfaces, the amount of unwashed cardiotomy suction blood returned to the patient, general health and preoperative organ function of the patient, blood loss and replacement, organ ischemia and reperfusion injury, sepsis, different degrees of hypothermia, periods of circulatory arrest, genetic profiles.

Excluding unwashed field blood from the perfusion circuit reduces admixture of high concentrations of thrombin, fibrinolysins, cytokines, activated complement,55 and leukocytes to the perfusate. Exclusion of these inflammatory mediators may be more important in reducing the amounts of vasoactive and cytotoxic substances circulating within the body than the heparin surface coating.

\section{Leukocyte Filtration}

The role of neutrophils in the acute inflammatory response has led to development of leukocyte-depleting filters for the CPB circuit. Consistent efficacy in reducing markers of neutrophil activation and improvement in respiratory or renal function are lacking. Washing cardiotomy suction blood and using leukodepleted allogenic red cell and platelet transfusions has reduced the interest in leukocyte filtration. Active sequestration of leukocytes and platelets using a separate cell separator may have beneficial effects, but requires a separate inflow cannula and separator system.

\section{Extracorporeal membrane oxygenation (ECMO)}

ECMO uses modified CPB technology to provide prolonged respiratory or cardiorespiratory support to patients of all ages who have failed conventional intensive care.56 Venous blood is drained into the ECMO circuit where it is oxygenated, carbon dioxide is removed and it is rewarmed before 
being returned to the body. It can be used to support any patient with severe but potentially reversible respiratory, cardiac, or multi-organ failure who does not have a contraindication to limited heparinization.

There are two types: venoarterial (VA) and venovenous (VV). The VA ECMO returns flow into a central artery. This flow is in addition to the native cardiac output. VV ECMO is dependent upon the patient having adequate cardiac function to pump oxygenated blood through the systemic circulation. It is used for the support of primary respiratory failure and not for support of failed cardiac function.

VA ECMO: used for support of cardiac and/or respiratory failure, Decrease preload to Right Ventricle (RV), Decrease preload an increase afterload to Left Ventricle (LV), Coronary perfusion potentially hypoxic, pulmonary blood flow markedly diminished at full flow, thromboembolism risk to the systemic circulation.

VV ECMO: Support of respiratory failure with stable cardiac function, No decrease in preload, Decreased afterload to RV, Coronaries perfused with well-oxygenated blood Pulmonary blood flow maintained with oxygenated blood, thromboembolism risk primarily to pulmonary circulation. [57]

\section{Miniaturized CPB}

Miniaturized CPB circuits have been developed with the objective of reducing the damaging effects of conventional CPB. It is hypothesized that minimizing hemodilution and mechanical blood trauma will improve outcomes. These closed circuits with little or no blood/air contact consist of a controlled vortex blood pump and a membrane oxygenator as the only components. There is no venous reservoir and no integral cardiac suction device. The components, including the tubing, are heparin coated.

Clinical studies in patients undergoing CABG suggest that use of these circuits is associated with fewer transfusions of blood products, less release of cardiac troponin, less postoperative atrial fibrillation, a lower prevalence of acute kidney injury, suppression of thrombin generation and coagulofibrinolytic activation, and lower levels of IL-6 and sc5b-9.58

Miniaturized circuits are associated with substantial reductions in neurologic injury, number of patients requiring transfusion of blood products, and peak cardiac troponin release.

\section{Conclusion}

CPB represent a crucial event in history of cardiac surgery. There are been described the determinants of safe perfusion, but the ideal variables of temperature, $\mathrm{pH}$, Hematocrit are still controversial. Further understanding of the pathophysiology of the perfusion system may resolve the debate.

The continuous generation of thrombin that overwhelms all the actual known anticoagulants is the cause of the thrombotic and bleeding complications associated, because produces a consumptive coagulopathy, which consumes coagulation factors and functional platelets. The development of a substance that completely inhibits the thrombin generation is a matter of work today.

The acute inflammatory response together with microembolization is responsible for most of the morbidity of CPB. It appears unlikely that drug cocktails or indirect measures directed against specific mediators of this response will prove more than mildly effective, given the magnitude and diversity of the acute inflammatory response. Miniaturized-CPB, micro-filters are some efforts on reduce damaging effects and produce more clinical benefits. 


\section{Competing interest}

None.

\section{Author's Contributions}

COL conceived, designed, conducted the literature review and drafted the manuscript. YCH, EFC, GLN, PPP, MB, MF revised and corrected the manuscript. All authors were equally involved in reading and approving the final manuscript.

\section{Acknowledgments}

To the perfusionst Teodoro Cubero, who supported the project and resolved all the doubts that arised during the writing of the manuscript.

\section{References}

1. Gollan F: Physioloogy of Cardiac Surgery. Hypothermia, Extracorporeal circulation and Extracorporeal Cooling. J Mich State Med Soc. 1959 Jan; 58(1): 53-76.

2. Cooley DA: Extracorporeal circulation in Cardiac Surgery. Surg Gynecol Obstet. 1958 May; 106 (5): 615-7.

3. Gibbon, JH: Artificial maintenance of circulation during experimental occlusion of pulmonary artery. Arch Surg 1937; 34: 1105.

4. Gibbon JH: Application of a mechanical heart and lung apparatus to cardiac surgery. Minn Med 1954; 37: 171.

5. Kirklin JW, DuShane JW, Patrick RT, Donald DE, Hetzel PS, Harshbarger HG, et al: Intracardiac surgery with the aid of a mechanical pump-oxygenator system (Gibbon type): report of eight cases. Mayo Clin Proc 1955; 30: 201.

6. Hypothermia, Circulatory Arrest, and Cardiopulmonary Bypass. In: Kouchoukos N, Blackstone E, Hanley F, Kirklin J, editors. Cardiac Surgery. 4th ed. Philadelphia: Elsevier; 2013. P. 67-132.

7. Hammon JW: Extracorporeal Circulation. In: Cohn LH, editor. Cardiac Surgery in the Adult. 3rd ed. New York: McGraw Hill; 2008. P. 349-414.

8. Hessel EA II, Edmunds LH: Extracorporeal Circulation: Perfusion Systems. In: Edmunds LH Jr, editor. Cardiac Surgery in the Adult. New York: McGraw-Hill; 2003. 317-338.

9. Griffin S, Pugsley W, Treasure T: Microembolism during cardiopulmonary bypass: a comparison of bubble oxygenator with arterial line filter and membrane oxygenator alone. Perfusion 1991; 6: 99.

10. Blauth $\mathrm{Cl}$, Smith PL, Arnold JV, et al: Influence of oxygenator type on the prevalence and extent of micro-emboli retinal ischemia during cardiopulmonary bypass: assessment by digital image analysis. J Thorac Cardiovasc Surg 1990; 99: 61.

11. Pearson DT: Gas exchange; bubble and membrane oxygenators. Semin Thorac Cardiovasc Surg 1990; 2: 313

12. Geissler HJ, Allen JS, Mehlhorn U, et al: Cooling gradients and formation of gaseous microemboli with cardiopulmonary bypass: an echocardiographic study. Ann Thorac Surg 1997; 64: 100.

13. Leschinsky BM, Zimin NK: Centrifugal blood pumps-a brief analysis: development of new designs. Perfusion 1991; 6: 115.

14. Boldt J: Volume therapy in cardiac surgery: does the kind of fluid matter? J Cardiothorac Vasc Anesth 1999; 13: 752.

15. Borger MA, Feindel CM: Cerebral emboli during cardiopulmonary bypass: effect of perfusionist interventions and aortic cannulas. J Extracorp Tech 2002; 34: 29.

16. Willcox TW: Vacuum-assisted venous drainage: to air or not to air, that is the question: has the bubble burst? J Extracorp Tech 2002; 34: 24. 
17. Jones TJ, Deal DD, Vernon JC, et al: How effective are cardiopulmonary bypass circuits at removing gaseous microemboli? J Extracorp Tech 2002; 34: 34.

18. Mitchell SJ, Wilcox T, Gorman DF: Bubble generation and venous air filtration by hard-shell venous reservoirs: a comparative study. Perfusion 1997; 12: 325.

19. Kincaid E, Jones T, Stump D, et al: Processing scavenged blood with a cell saver reduces cerebral lipid microembolization. Ann Thorac Surg 2000; 70: 1296.

20. Cook DJ, Zehr KJ, Orszulak TA, Slater JM: Profound reduction in brain embolization using an endoaortic baffle during bypass in swine. Ann Thorac Surg 2002; 73: 198.

21. Macoviak JA, Hwang J, Boerjan KL, Deal DD: Comparing dual stream and standard cardiopulmonary bypass in pigs. Ann Thorac Surg 2002; 73: 203.

22. Reichenspurner H, Navia JA, Benny G, et al: Particulate embolic capture by an intra-aortic filter device during cardiac surgery. $J$ Thorac Cardiovasc Surg 2000; 119:233.

23. Weinstein GS: Left hemispheric strokes in coronary surgery: implication for end-hole aortic cannulas. Ann Thorac Surg 2001; 71:128.

24. Brooker RF, Brown WR, Moody DM, et al: Cardiotomy suction: a major source of brain lipid emboli during cardiopulmonary bypass. Ann Thorac Surg 1998; 65:1651.

25. Downing SW, Edmunds LH Jr: Release of vasoactive substances during cardiopulmonary bypass. Ann Thorac Surg 1992; 54:1236.

26. Little AG, Lin CY, Wernley JA, et al: Use of the pulmonary artery for left ventricular venting during cardiac operations. J Thorac Cardiovasc Surg 1984; 87:532.

27. Casha AR: A simple method of aortic root venting for CABG. Ann Thorac Surg 1998; 66:608.

28. Clements F, Wright SJ, deBruijn N: Coronary sinus catheterization made easy for port-access minimally invasive cardiac surgery. J Cardiothorac Vasc Anesth 1998; 12:96.

29. Honkonen EL, Kaukinen L, Pehkoneu EJ, Kaukinen S: Myocardial cooling and right ventricular function in patients with right coronary artery disease: antegrade vs. retrograde cardioplegia. Acta Anaesthesio/ Scand 1997; 41:287.

30. Liam B-L, Plöchl W, Cook DJ, et al: Hemodilution and whole body oxygen balance during normothermic cardiopulmonary bypass in dogs. J Thorac Cardiovasc Surg 1998; 115:1203.

31. Tominaga R, Smith WA, Massiello A, et al: Chronic nonpulsatile blood flow, I: cerebral autoregulation in chronic nonpulsatile biventricular bypass: carotid blood flow response to hypercapnia. J Thorac Cardiovasc Surg 1994; 108:907.

32. Lindholm L, Hansdottir V, Lundqvist M, Jeppsson A: The relationship between mixed venous and regional venous oxygen saturation during cardiopulmonary bypass. Perfusion 2002; 17:133.
33. Sugurtekin $H$, Boston US, Cook DJ: Bypass flow, mean arterial pressure, and cerebral perfusion during cardiopulmonary bypass in dogs. J Cardiothorac Vasc Anesth 2000; 14:25.

34. Sadahiro M, Haneda K, Mohri H: Experimental study of cerebral autoregulation during cardiopulmonary bypass with or without pulsatile perfusion. J Thorac Cardiovasc Surg 1994; 108:446.

35. Schwartz AE, Sandhu AA, Kaplan RJ, et al: Cerebral blood flow is determined by cardiopulmonary bypass arterial pressure and not cardiopulmonary bypass flow rate. Ann Thorac Surg 1995; 60:165.

36. Cook DJ, Orszulak TA, Daly RC: Minimum hematocrit at differing cardiopulmonary bypass temperatures in dogs. Circulation 1998; 98(Suppl II):II-170.

37. Cook DJ: Optimal conditions for cardiopulmonary bypass. Semin Cardiothorac Vasc Anesth 2001; 5:265.

38. Liam B-L, Plöchl W, Cook DJ, et al: Hemodilution and whole body oxygen balance during normothermic cardiopulmonary bypass in dogs. J Thorac Cardiovasc Surg 1998; 115:1203.

39. Khatri P, Babyak M, Croughwell ND, et al: Temperature during coronary artery bypass surgery affects quality of life. 2001; 71:110.

40. Jonas RA: Optimal pH strategy for hypothermic circulatory arrest. J Thorac Cardiovasc Surg 2001;121:204.

41. Bellinger DC, Wypij D, du Plessis AJ, Rappaport LA, Riviello J, Jonas RA, et al: Developmental and neurologic effects of alphastat versus $\mathrm{pH}$-stat strategies for deep hypothermic cardiopulmonary bypass in infants. J Thorac Cardiovasc Surg 2001;121: 374-83.

42. Pearl JM, Thomas DW, Grist G, Duffy JY, Manning PB: Hyperoxia for management of acid-base status during deep hypothermia with circulatory arrest. Ann Thorac Surg 2000; 70: 751-5.

43. Edmunds LH Jr, Stenach N: The blood surface interface. In Gravlee GP, Davis RF, Kurusz M, Utley JR (eds): Cardiopulmonary Bypass: Principles and Practice, 2nd ed. Media, Pa, Williams \& Wilkins, 2000; p 149.

44. Aldea GS, O'Gara P, Shapira OM, et al: Effect of anticoagulation protocol on outcome in patients undergoing CABG with heparin-bonded cardiopulmonary bypass circuits. Ann Thorac Surg 1998; 65:425.

45. Bowen FW, Edmunds LH Jr: Coagulation, anticoagulation, and the interaction of blood and artificial surfaces. In Zwischenberger JB, Steinhorn RH, Bartlett RH (eds): ECMO Extracorporeal Cardiopulmonary Support in Critical Care. Extracorporeal Life Sup- port Organization Publication, 2000.

46. Hirsh J, Colman RW, Marder VJ, et al: Overview of thrombosis and its treatment. In Colman RW, Hirsh J, Marder VJ, et al (eds): Hemostasis and Thrombosis: Basic Principles and Practice. Philadelphia, Lippincott Williams \& Wilkins, 2001; p 1071. 
47.Edmunds LH Jr: Inflammatory response to cardiopulmonary bypass. Ann Thorac Surg 1998; 66:S12.

48. Warren JS, Ward PA: The inflammatory response. In Beutler $E$, Coller BS, Lichtman MA, et al (eds): Williams Hematology, 6th ed. New York, McGraw-Hill, 2001; p 67.

49. Ember JA, Jagels MA, Hugli TE: Characterization of complement anaphylatoxins and their biological responses. In Volankis JE, Frank MM (eds): The Human Complement System in Health and Disease. New York, Marcel Dekker, 1998; p 241.

50. Smolen JE, Boxer LA: Functions of neutrophils. In Beutler $E_{\text {, }}$ Coller BS, Lichtman MA, et al (eds): Williams Hematology, 6th ed. New York, McGraw-Hill, 2001; p 761.

51. Francis CW, Marder VJ: Physiologic regulation and pathologic disorders of fibrinolysis. In Colman RW, Hirsh J, Marder VJ, et al (eds): Hemostasis and Thrombosis: Basic Principles and Practice. Philadelphia, Lippincott Williams \& Wilkins, 2001; p 975.

52. Hajjar KA, Esmon NL, Marcus AJ, Muller WA: Vascular function in hemostasis. In Beutler E, Coller BS, Lichtman MA, et al: Williams Hematology, 6th ed. New York, McGraw-Hill, 2001; p 1451.

53. Funk CD: Platelet eicosanoids. In Colman RW, Hirsh J, Marder VJ, et al (eds): Hemostasis and Thrombosis: Basic Principles and Practice. Philadelphia, Lippincott Williams \& Wilkins, 2001; $p$ 533.

54. Fukami MH, Holmsen $H$, Kowalska A, Niewiarowski S: Platelet secretion. In Colman RW, Hirsh J, Marder VJ, et al (eds): Hemostasis and Thrombosis: Basic Principles and Practice. Philadelphia, Lippincott Williams \& Wilkins, 2001; p 559.

55. Hattori T, Khan MMH, Coleman RW, Edmunds LH: Plasma tissue factor plus activated peripheral mononuclear cells activate factors VII and X in cardiac surgical wounds. J Am Coll Cardiol 2005; 46:707.

56. Charles B, Peek G: Extracorporeal Membrane Oxygenation (ECMO) for adults in Respiratory Failure. In: Waldmann C, Soni N, Rhodes A. Oxford Desk Reference. Critical Care. New York, Oxford University Press, 2008; p 32.

57.Fiser RT: Extracorporeal Life Support. In Wheeler DS, Wong HR, Shanley TP (eds): Pediatric Critical Care Medicine. Volume 2: respiratory, Cardiovascular and Central Nervous Systems. Verlag, London. Springer, 2014; p 220

58. Nakahira A, Sasaki Y, Hirai H, Fukui T, Matsuo M, Takahashi $Y$, et al. Closed cardiopulmonary bypass circuits suppress thrombin generation during coronary artery bypass grafting. Interact Cardiovasc Thorac Surg 2010; 10:555-60.

\section{Comment on this article:}

\section{$\mathbf{f ( B )}$ in $8+\mathbf{S} P$}

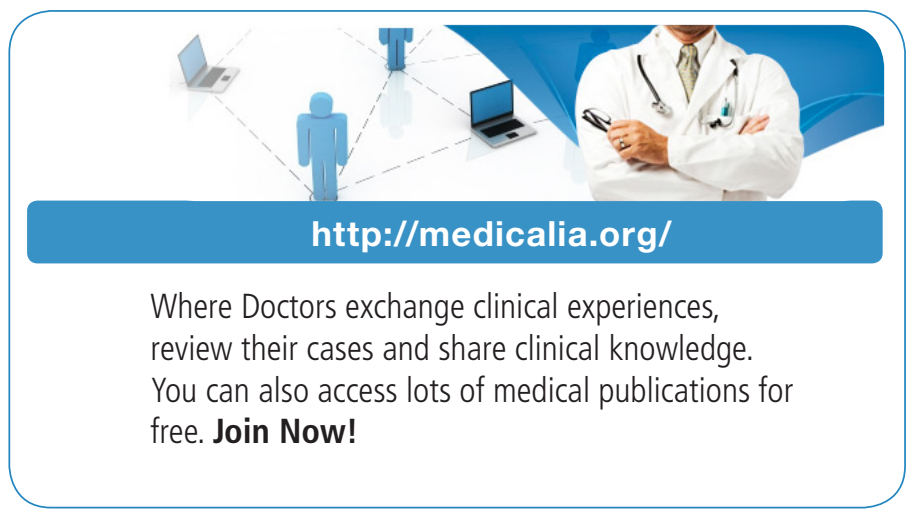

\section{Publish with iMedPub}

\section{http://www.imed.pub}

International Archives of Medicine is an open access journal publishing articles encompassing all aspects of medical science and clinical practice. IAM is considered a megajournal with independent sections on all areas of medicine. IAM is a really international journal with authors and board members from all around the world. The journal is widely indexed and classified Q1 in category Medicine. 